\title{
A IMPORTÂNCIA DAS MICRO E PEQUENAS EMPRESAS PARA O CRESCIMENTO DO PAÍS
}

\author{
THE IMPORTANCE OF MICRO AND SMALL ENTERPRISES FOR THE GROWTH \\ OF THE COUNTRY
}

Vitor Fonceca Xavier- vitor-f-xavier@hotmail.com

Moacir José Bertaci- moacir.bertaci@fatectq.edu.br

Faculdade de Tecnologia de Taquaritinga (FATEC) - SP - Brasil

DOI: 10.31510/infa.v15i2.392

\begin{abstract}
RESUMO
O número de empresas de pequeno porte vem crescendo dia após dia, e esse fato se explica devido a grande crise de desemprego que afeta milhares de brasileiros e ao espírito empreendedor do brasileiro. A dificuldade financeira faz com que as pessoas encontrem no empreendedorismo uma solução para retornar ao mercado de trabalho. Atualmente os pequenos negócios geraram 13 vezes mais empregos do que as médias e grandes empresas e esse aumento trouxeram inúmeros benefícios, contribuindo para o desenvolvimento das cidades e regiões em todo o país, sendo responsável por $27 \%$ do PIB (Produto Interno Bruto). Dentre vários setores das micro e pequenas empresas, a agropecuária foi o segmento que mais se destacou na geração de novas vagas. E neste contexto, o objetivo desse trabalho é identificar e diferenciar através de pesquisas bibliográficas, sites, revistas e anais os tipos de empresas de pequeno porte, quais os setores que mais ofereceram vagas, como são classificadas, os fatores que induzem as pessoas a se tornarem empresários.
\end{abstract}

Palavras-chave: Empresas. Empreendedorismo. Micro e Pequenas Empresas. Emprego.

\begin{abstract}
The number of small businesses is growing day by day, and this fact should explain due to the great unemployment crisis that affects the Brazilians and the entrepreneurial spirit of the Brazilian. The financial situation makes people in entrepreneurship a solution to return to the job market. Small businesses generated 13 times more jobs than medium-sized and large companies and those that were most important in terms of benefits, contributing to the development of cities and regions across the country, accounting for 27\% of GDP. Among the micro and small companies, an agricultural sector was the segment that stood out the most in the generation of new vacancies. And in this context, the job is to identify and differentiate through bibliographic searches, websites, journals and annals the types of small businesses, which are the sectors that most offer vacancies, how they are classified, the most important that people become business.
\end{abstract}


Keyword: Small Businesses. Entrepreneurial. Job. Companies.

\section{INTRODUÇÃO}

O SEBRAE (2011) destaca que os negócios de pequeno porte, vem contribuindo para geração de 1,2 milhões de novos empreendimentos formais. Desta forma, mais de $99 \%$ são Micro e Pequenas Empresas e Microempreendedores Individuais (MEI) colaborando por mais da metade dos empregos com carteira assinada, e assim correspondendo a $27 \%$ do Produto Interno Bruto (PIB) representando um papel importantíssimo para a economia do Brasil.

De acordo com a pesquisa realizada pela Global Entrepreneurship Monitor (GEM) (2015), constatou que ter um negócio próprio é o principal sonho de $34 \%$ dos adultos brasileiros, entre 18 e 64 anos. A pesquisa também comprovou que quatro em cada dez brasileiros são donos de uma empresa, a maioria de pequeno porte ou estão envolvidos com a criação do próprio negócio.

Silva (2004) declara que uma das imprescindíveis formas descobertas na luta contra o desemprego é a criação de novos negócios, onde pessoas qualificadas, que possuem conhecimento e associado a um perfil empreendedor assumem a missão de desenvolver sua própria empresa e com isso gerar produção, renda e em seguida, novos postos de trabalho.

Conforme cita o autor Degen (2005) é essencial identificar as falhas responsáveis pela mortalidade precoce consequentemente essas falhas podem ser provocadas por conta dos gestores no momento da criação e gestão de seus negócios, juntamente com outros fatores, como, a ausência de um comportamento empreendedor e a falta de planejamento, pois para que uma empresa alcance êxito é indispensável que antes de abri-la se faça um estudo prévio de todos os aspectos do negócio, como: localização, concorrência, públicoalvo, custos fixos e variáveis, portanto é necessário ter domínio de conhecimentos sobre aquilo que se quer empreender.

De acordo com Silva (2004) é essencial que as empresas de pequeno porte sejam capazes de apresentar maior flexibilidade no momento de lidar com os problemas, pois é através destas dificuldades que as tornaram cada vez mais inovadoras cumprindo com todas as exigências impostas pelo mercado.

Com isso, o objetivo deste trabalho é diferenciar tipos de empresas de pequeno porte, pesquisar o mercado, identificar as dificuldades e oportunidades, tudo isso deve ser analisado conscientemente não só no momento de abrir um negócio próprio, mas também 
em todos os estágios de desenvolvimento da empresa, pelo fato de cada dia existir um novo desafio, com novas oportunidade e conquistas.

\section{FUNDAMENTAÇÃO TEÓRICA}

\subsection{Classificação das empresas de pequeno porte}

Segundo dados do SEBRAE (2018) os pequenos negócios são divididos da seguinte maneira:

Tabela 1 - Classificação dos pequenos negócios

\begin{tabular}{c|c}
\hline Porte & Faturamento Bruto Anual \\
\hline MEI - Microempreendedor individual & $\mathrm{R} \$ 81.000,00$ \\
\hline ME - Microempresa & $\mathrm{R} \$ 360.000,00$ \\
\hline EPP - Empresa de Pequeno Porte & $\mathrm{R} \$ 4.800 .000,00$ \\
\hline \multicolumn{2}{c}{ Fonte: SEBRAE (2018) }
\end{tabular}

\section{MEI - Microempreendedor Individual}

De acordo com o SEBRAE (2018) o microempreendedor Individual, é o trabalhador que trabalha por conta própria e se regulariza como pequeno empresário optante pelo Simples Nacional, com receita bruta anual de até R \$ 81.000,00. O microempreendedor pode possuir um único empregado e não pode ser sócio ou titular de outra empresa.

\section{ME - Microempresa}

Segundo o SEBRAE (2018) é qualquer empreendimento que tem receita bruta anual inferior ou igual a R\$ 360 mil. Para formalização é necessário definir entre uma das formas de tributação (Simples Nacional, Lucro Real ou Lucro Presumido) e executar o registro em uma Junta Comercial.

\section{EPP - Empresa de Pequeno Porte}

Segundo o SEBRAE (2018), a Empresa de Pequeno Porte deve ter um faturamento anual no limite de $\mathrm{R} \$ 4,8$ milhões, assim como a microempresa, o titular de uma Empresa de Pequeno Porte deve formalizar o negócio em uma Junta Comercial, optando por um dos regimes tributários (Simples Nacional Lucro Real ou Lucro Presumido).

\subsection{Empreendedorismo}

Chiavenato (2008) afirma que existe inúmeras razões pelo qual muitas pessoas criam seu próprio negócio e assumem riscos, se seguir cuidadosamente as instruções possivelmente conseguirá sua independência trabalhista e financeira. 
Dolabela (2001) declara que o grau de empreendedorismo no Brasil é alto por causa do grande número de pessoas desempregadas, ou seja, se a pessoa não abre o próprio negócio, poderá sofrer necessidades. Segundo o autor outro fator que aumenta o empreendedorismo no país é o fato das pessoas estarem buscando novas escolhas de sobrevivência e não porque identificaram uma oportunidade no mercado de trabalho.

Segundo Chiavenato (2008) as principais razões que despertam o empreendedorismo nas pessoas são o desejo de ser seu próprio patrão; o poder colocar suas ideias em prática; trabalhar no ramo gosta; ter a oportunidade de ganhar mais que quando era simples empregado; a descoberta de uma oportunidade inovadora; e a oportunidade de aplicar seus próprios recursos e habilidades pessoais;

Para Dornelas (2008), a capacidade de possuir visão e empreender necessita de uma busca por oportunidades e esforços. Possuir um conhecimento aprofundado na área que pretende atuar, incluindo tempos de estudos, e desta forma ira proporcionar habilidades e experiências ao profissional. Ainda de acordo com o autor os empreendedores precisam ter visão em longo prazo sobre seus negócios, possuir as competências no momento de tomar as decisões corretas. Os pequenos empresários tem a habilidade de perceber em pequenas coisas a chance de progredir, evoluir e alcançar objetivos.

Segundo o SEBRAE (2017) foi realizado uma pesquisa quantitativa, com 6.617 entrevistados, com o objetivo de identificar qual é beneficio de se tornar um empresário conforme segue o Gráfico 1.

\section{Gráfico 1 - Benefício de se Tornar um Empreendedor}

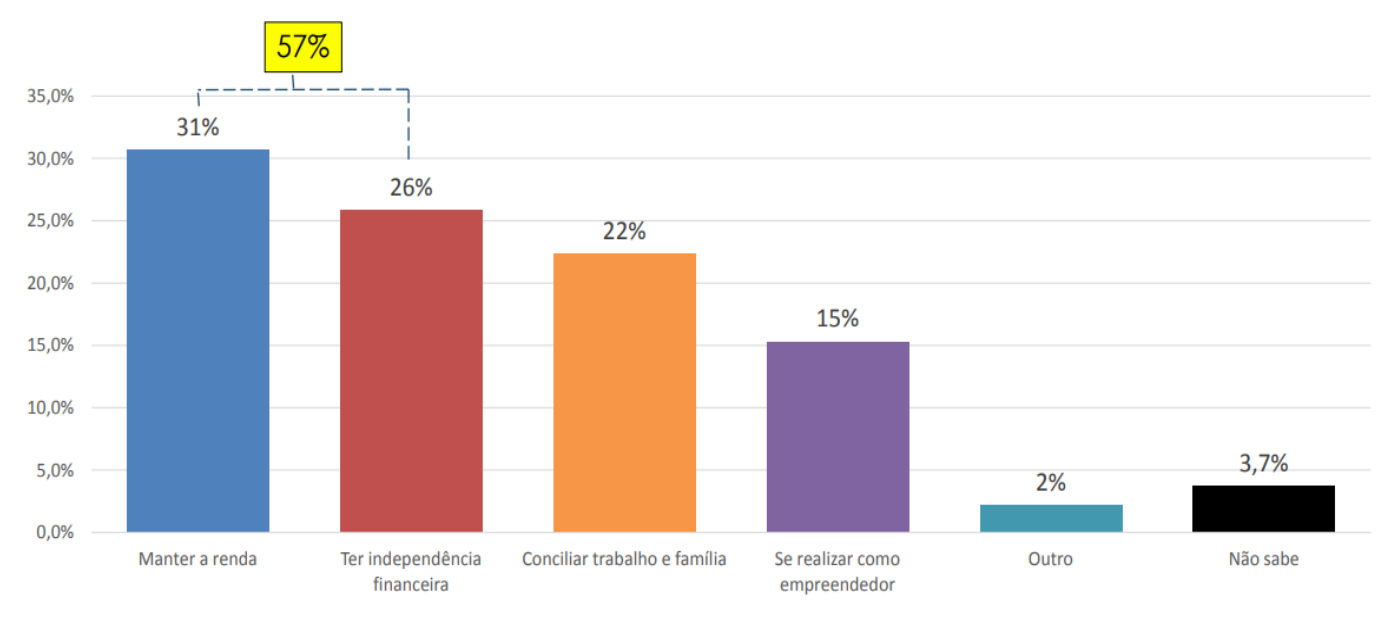

Fonte: CAGED/SEBRAE (2017) 
De acordo com a pesquisa do SEBRAE (2017) é possível observar que manter a renda e possuir independência financeira são citados por $57 \%$ dos empreendedores como os principais benefícios de se tornar dono do seu próprio negócio, de acordo com os entrevistados conseguir harmonizar o horário de trabalho junto com a vida familiar, é segundo principal beneficio de se tornar empreendedor, correspondendo a $22 \%$ dos entrevistados, se realizar como empreendedor corresponde por $15 \%$ dos entrevistados, seguido por $5,7 \%$ que possuem outros motivos ou ainda não sabem.

\title{
3 PROCEDIMENTOS METODOLÓGICOS
}

\subsection{A importância das Micro e Pequenas empresas na economia do País.}

\begin{abstract}
As Micro e Pequenas empresas desempenham um papel de extrema importância no cenário econômico brasileiro, pois respondem por boa parte das ocupações geradas e contribuem para um grande percentual do PIB. A representatividade das Micro e Pequenas Empresas para a economia brasileira pode ser entendida através dos seguintes dados do SEBRAE (2007).
\end{abstract}

Segundo um levantamento do SEBRAE (2017), mostrou que os pequenos negócios geraram 13 vezes mais empregos do que as médias e grandes empresas. Os pequenos negócios abriram 351,6 mil vagas no período, enquanto os de médio e grande porte abriram apenas 27,2 mil.

Gráfico 2 - Levantamento do SEBRAE sobre criação de pequenos negócios Em milhares

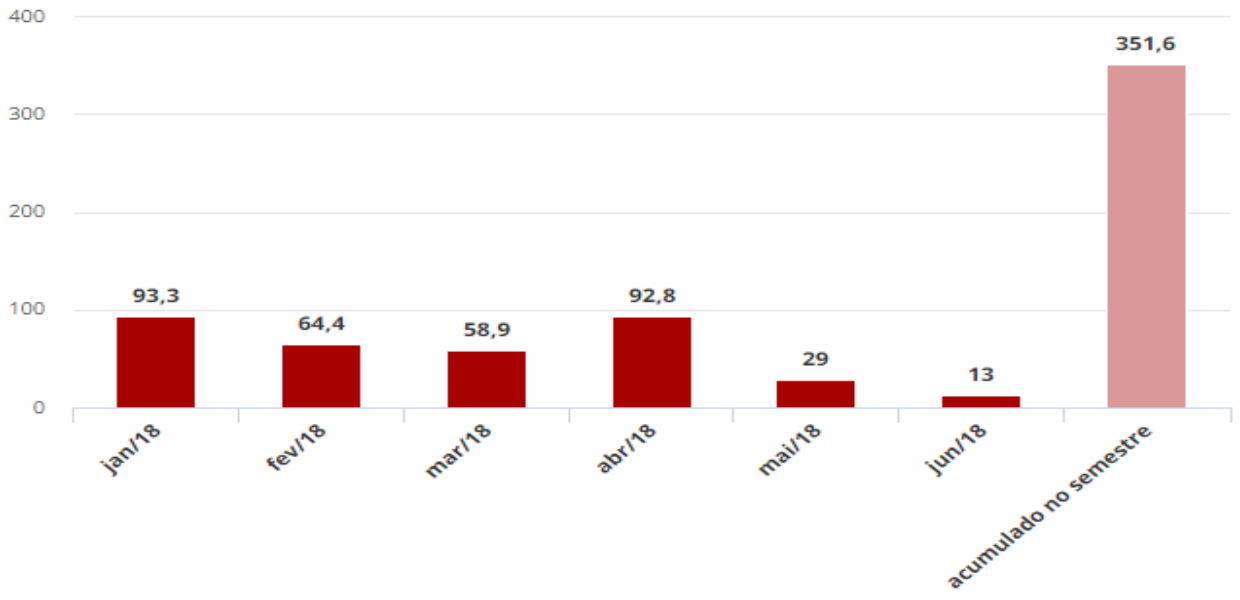

Fonte: SEBRAE (2017) 
Silva (2004) afirma que a importância das micro e pequenas tem sido discutida em vários países, com o objetivo de fortalecer os investimos para esses empreendimentos, pois na maior parte dos países desenvolvidos as empresas de pequeno porte tem um papel fundamental na produção industrial contribuindo para o aumento dos postos de trabalho.

De acordo com o levantamento do SEBRAE (2017) o primeiro semestre, as pequenas empresas dos setores da construção civil e da indústria da transformação fecharam mais vagas do que abriram. No outro extremo, a agropecuária foi o segmento que mais gerou empregos.

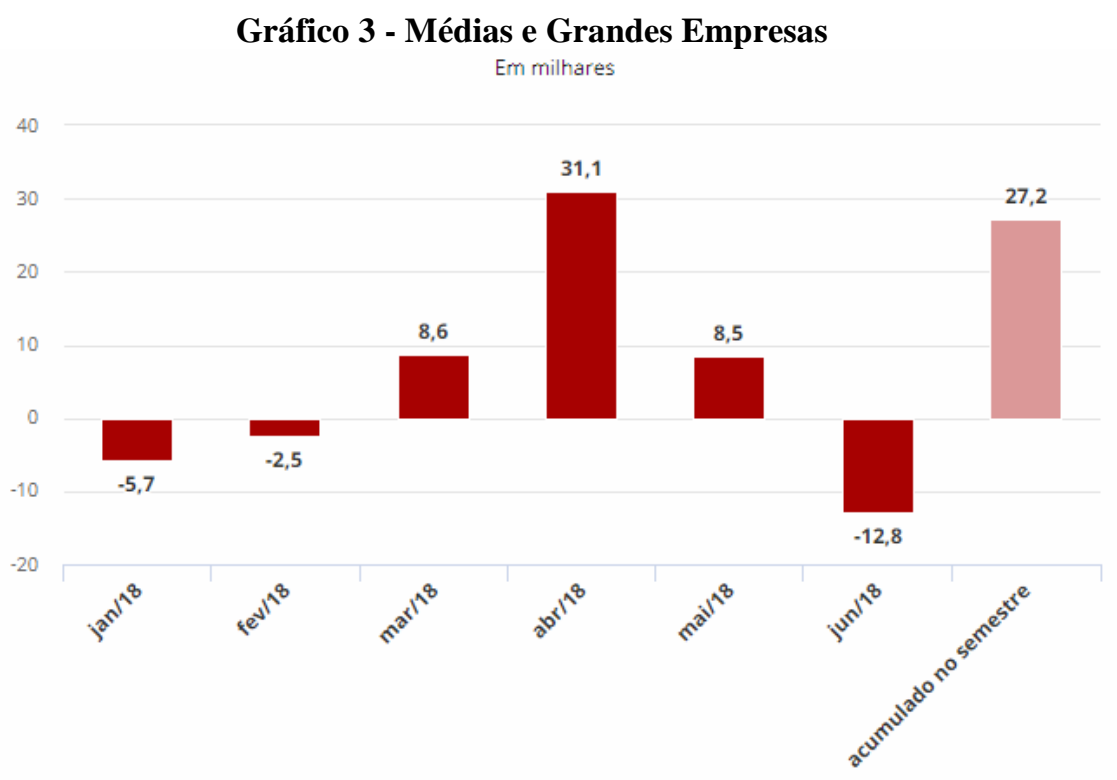

Fonte: SEBRAE (2017)

Ao observar o Gráfico 4, é possível perceber que as pequenas e micro empresas possuem um papel importantíssimo para o país, tanto pela enorme capacidade de criar empregos, ou pelo número de estabelecimentos. E dessa forma, contribuem expressivamente para a economia do Brasil. 
Gráfico 4 - Empregos gerados pelos pequenos negócios em julho, por setor

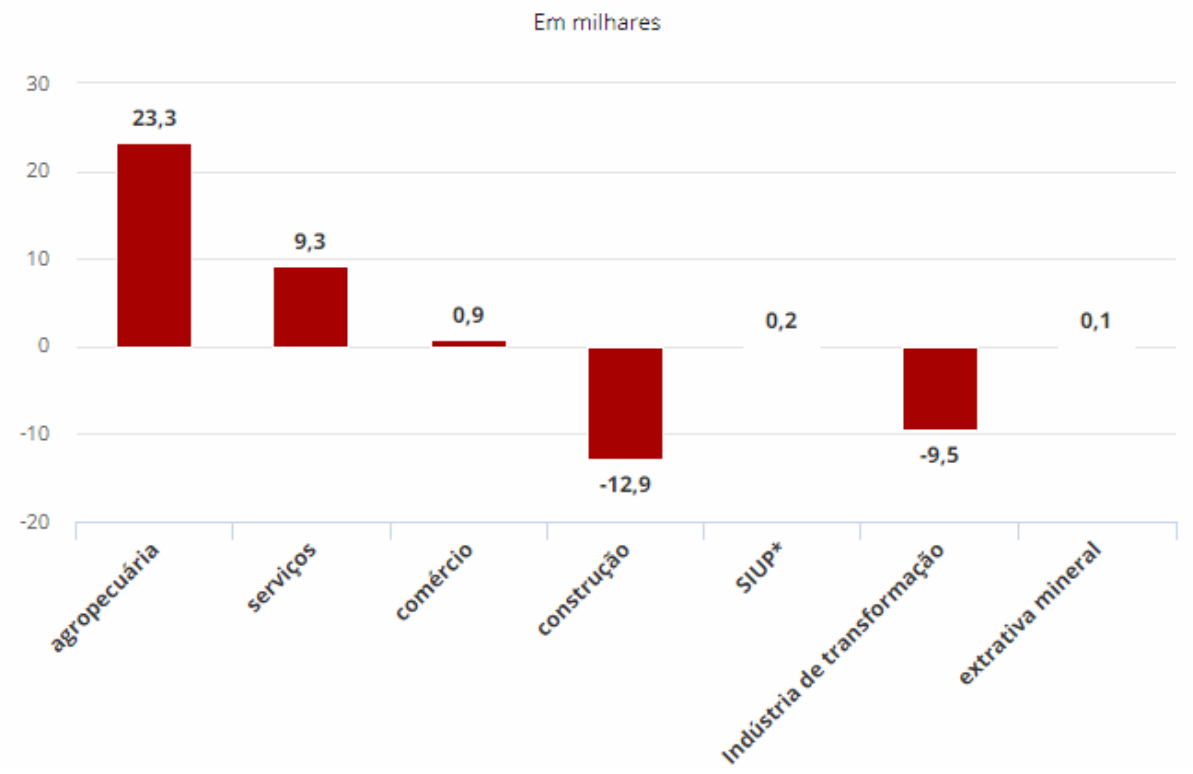

Fonte: SEBRAE (2017)

\section{RESULTADO E DISCUSSÃO}

\subsection{Problemas e Dificuldades das Micro e Pequenas Empresas.}

Existem mais de 9 milhões de Micro e pequenas empresas no país que, representam mais de um quarto do Produto Interno Bruto (PIB) nacional sendo assim responsáveis por uma grande parte do giro econômico brasileiro. Entretanto, muitas dessas empresas enfrentam dificuldades que as levam a fechar as portas precocemente. Entre os principais problemas, estão o excesso de burocracia para a obtenção de créditos, a ausência de planejamento e a alta carga tributária.(VOLPI,2017)

De acordo Exame (2015), os pequenos empresários apresentam três dificuldades principais: na escolha inicial do ramo de negócio que é feita de forma superficial, capital insuficiente e capacidade gerencial péssima. Isso corresponde com a maioria dos pequenos empresários, que criam seus negócios com base na facilidade de entrada em determinado ramo, não em estudos sobre mercado, matéria prima, principais concorrentes.

Barbosa (2018) salienta que as pequenas e médias empresas estão com problemas em colocar seus produtos em um mercado cada vez mais competitivo e exigente; nos equipamentos, técnicas, e processos de produção que são, na maioria, ultrapassados e com isso aumenta os custos operacionais excessivos e a baixa qualidade dos produtos que ocorre pela falta de capital de giro e financiamento; escassez de matéria prima ou baixa qualidade; 
instabilidade do mercado consumidor; falta de mão de obra adequada; burocracia e complexidade de legislações fiscais; falta de capacidade gerencial na administração e organização dos vários setores de suas atividades.

\subsection{Mortalidade Precoce das Micro e Pequenas Empresas.}

Segundo o SEBRAE (2016), a probabilidade de mortalidade é maior entre os empresários que estavam desempregados antes de abrir o negócio, pelo fato da pouca experiência no ramo, e com isso acabam abrindo o negócio por necessidade, e não tiveram tempo suficiente para planejar, não conseguiram negociar com fornecedores, não conseguiram empréstimos em bancos, não aprimoraram os produtos ou serviços, não investiram na capacitação da mão-de-obra, não buscaram inovar, não acompanhavam as receitas e despesas, não diferenciavam seus produtos e não investiam na sua própria capacitação em gestão empresarial.

No quadro abaixo são apresentadas as razões da mortalidade das empresas no Brasil, ordenadas por importância, na visão dos empresários que responderam à pesquisa do SEBRAE. (VELDEN,2004)

Quadro 1 - Causas da mortalidade das MPEs em 2004

\begin{tabular}{|c|l|l|}
\hline \multirow{5}{*}{ Falhas Gerenciais } & $1^{\circ}$ & Falta de capital de giro \\
\cline { 2 - 3 } & $3^{\circ}$ & Problemas financeiros \\
\cline { 2 - 3 } & $8^{\circ}$ & Ponto/ local inadequado \\
\cline { 2 - 3 } & $9^{\circ}$ & Falta de conhecimentos gerenciais \\
\hline \multirow{2}{*}{ Causas econômicas conjunturais } & $2^{\circ}$ & Falta de clientes \\
\cline { 2 - 3 } & $4^{\circ}$ & Maus pagadores \\
\cline { 2 - 3 } & $6^{\circ}$ & Recessão econômica no país \\
\hline \multirow{4}{*}{ Logística operacional } & $12^{\circ}$ & Instalação inadequadas \\
\hline \multirow{3}{*}{ Políticas Publicas e arcabouço legal } & $11^{\circ}$ & Falta de mão de obra qualificada \\
\cline { 2 - 4 } & $5^{\circ}$ & Falta de credito bancário \\
\cline { 2 - 4 } & $10^{\circ}$ & Problemas com a fiscalização \\
\cline { 2 - 4 } & $13^{\circ}$ & Carga tributária elevada \\
\cline { 2 - 3 } & $7^{\circ}$ & Outra razão \\
\hline
\end{tabular}


Para o SEBRAE (2018), as dificuldades mais relevantes ao êxito dos negócios no país são: o baixo nível de escolaridade e renda do empreendedor, que por falta de crédito junto às instituições financeiras, utiliza capital próprio ou da família, e acabam limitando o crescimento da empresa tornando vulnerável às oscilações e a sazonalidade do mercado.

\subsection{Fatores que Contribuem para o Sucesso.}

Dornelas (2007) afirma que os empreendedores que realizam seu trabalho por prazer, desenvolvem um entusiasmo que acaba se tornando o principal combustível que os mantém cada vez mais animados e autodeterminados, tornando-os perseverantes e convictos de seu negócio próprio.

Pillegge (2016) informa que no início de um empreendimento novo no mercado, é necessário obter uma visão de oportunidade de crescimento, enfatizando que o empresário deve ser capaz de criar um negócio rentável. Na visão do autor, a função não é trabalhar para o negócio, mas sim trabalhar o negócio.

Na visão de Rocha (2008), os principais fatores que contribuem para o sucesso de uma empresa são: possuir capacidade empreendedora; possuir um planejamento/Plano de negócio; criatividade; persistência; aproveitar as oportunidades de mercado; conhecimento de mercado; reinvestimento dos lucros; e utilizar capital próprio.

Mattos (2008) afirma inovar em processos é um fator relevante para as micro e pequenas empresas, pois torna a empresa mais competitiva, reduz custos, aumenta a qualidade, melhora as condições de trabalho e contribui para o aumento da produtividade.

De acordo com Dornelas (2007) uma rede de contatos bem estabelecida é um habito presente aos micro e pequenos empreendedores de sucesso, eles sabem criar uma rede de contatos que os auxiliam a empresa, junto aos clientes, fornecedores.

Na visão de Rocha (2016), o sucesso das micro e pequenas empresas podem ser descritos por meio de três pilares fundamentais que são os processos, as pessoas e os produtos.

\subsection{SEBRAE Como Parceiro dos Pequenos Empreendedores}

Palermo (2002) afirma que a criação do Serviço Brasileiro de Apoio ás Micro e Pequenas Empresas (SEBRAE) foi fundamental, pois oferece total apoio para os micro e 
pequenos empresários, contribuindo para o bom desenvolvimento do seu negócio e das suas atividades empresarias de pequeno porte.

O autor, ainda destaca que o Sebrae oferece um conjunto de serviços de apoio e orientação, tais como: cursos, palestras, consultorias, rodadas de negócios, orientações técnicas e com a vantagem de oferecer todos esses benefícios de maneira gratuita, facilitando e incentivando os futuros empresários e aqueles que já atuam no ramo do empreendedorismo.

Para Dolabela (1999) após a criação de iniciativas que apoiassem os empresários de pequeno porte, como o SEBRAE, o cenário nacional foi acelerando, pois os empreendedores foram ganhando maior confiança em abrir seu próprio negócio.

\section{CONCLUSÃO}

Neste artigo foi analisada a importância das micro e pequenas empresas para o país visto que exercerem papel relevante na geração de emprego, contribuindo na economia e representando uma parcela considerável no PIB e dessa forma colabora para o desenvolvimento das cidades e regiões em todo o território nacional.

Conforme demonstrado no presente trabalho há diversos fatores que podem contribuir para o bom desempenho e sucesso do empreendimento, como citado anteriormente, ter um planejamento prévio, juntamente com um plano de negócio é de extrema importância, pois o pequeno empresário terá uma ferramenta de orientação na busca de informação. Habilidades empreendedoras como a criatividade e a persistência são valiosíssimas no cenário atual, o empreendedor que souber conciliar tais habilidades juntamente com seu conhecimento na área, será capaz de identificar as oportunidades de mercado e por consequência terá vantagens competitiva com seus concorrentes.

A mortalidade e a curta vida das micro e pequenas empresas são problemas graves que atinge não somente os empresários, mas também os empregados e seus familiares, além de atingir o meio social no qual estão inseridos.

Entre os diversos problemas citados que causam e geram a mortalidade das Pequenas Empresas estão relacionados à gestão deficiente da empresa, tal fato pode ser justificado conforme foi abordado pelo SEBRAE, que identificou que a mortalidade é maior nos empresários que estavam desempregados antes de abrir o seu próprio negócio, por conta 
disso acabam entrando em um ramo que não possuem experiência pelo fato da necessidade e isso acaba acarretando diversos problemas que por final levam a falência.

Para diminuir o numero da mortalidade, os empresários podem contar com o SEBRAE que possui o objetivo de auxiliar o desenvolvimento das Micro e Pequenas Empresas e assim estimulando o empreendedorismo no país.

O SEBRAE pode oferecer um conjunto de serviços como cursos, palestras, consultorias e deste modo facilitando e amparando as pessoas que sonham em ter seu próprio negócio, pessoas que já atuam e até mesmo pra quem pretende ampliar sua empresa.

\section{REFERÊNCIAS}

BARBOSA, Rodrigo Eduardo. Capital de giro: conceito e importância para seu negócio. 2018. Disponível em: <http://sebraemgcomvoce.com.br/capital-de-giro-conceito-eimportancia-para-seu-negocio/>. Acesso em: 26 nov. 2018..

CHIAVENATO, Idalberto. Empreendedorismo: dando asas ao espírito empreendedor. São Paulo: Editora Saraiva, 2008.

DEGEN, Ronald. O empreendedor: fundamentos da iniciativa empresarial. São Paulo: Markon Books, 2005.

DOLABELA, F. Oficina do Empreendedor: a metodologia de ensino que ajuda a transformar conhecimento em riqueza. São Paulo: Cultura Editores Associados; 1999.

DOLABELA, F. Oficina do Empreendedor: a metodologia de ensino que ajuda a transformar conhecimento em riqueza. São Paulo: Cultura Editores Associados, 2001

DORNELAS, J. C. A. Empreendedorismo: transformando ideias em negócios. 3. ed. Rio de janeiro: Elsevier, 2008.

Exame. 5 indicadores para medir o sucesso do seu negócio. 2015. Disponível em: <https://exame.abril.com.br/pme/5-indicadores-para-medir-o-sucesso-do-seu-negocio/>. Acesso em: 26 nov. 2018.

GEM. Empreendedorismo no Brasil, 2015.

Disponível em:

https://bibliotecas.sebrae.com.br/chronus/ARQUIVOS_CHRONUS/bds/bds.nsf/c6de907fe0 574c8ccb36328e24b2412e/\$File/5904.pdf. Acesso em 25 ago 2018.

MATTOS, F. et al. Kit Metodológico Para Inovação Empresarial. Brasília: movimento competitivo, 2008. 36p 
PALERMO, F. K. de O. As micro e pequenas empresas como propulsoras do desenvolvimento econômico e social: contribuição para o incremento das atividades econômicas no âmbito do Mercosul. Jus Navigandi, Teresina, ano 7, n. 55, 1 mar. 2002.

PILLEGGI, Marcus Vinicius. As principais características de um empreendedor de sucesso. 2016. Disponível em: <https://revistapegn.globo.com/Noticias/noticia/2014/07/principaiscaracteristicas-de-um-empreendedor-de-sucesso.html>. Acesso em: 26 nov. 2018

ROCHA, H. Pesquisa quantitativa, 2008. Disponível em:

http://www.heliorocha.com.br/graduacao/publicidade/download/MEP/MEPPesquisaQuantit at iva.doc. Acesso em 15 ago. 2018.

ROCHA, Marcos. Pilares de sucesso. 2016. Disponível em:

$<$ http://www.administradores.com.br/mobile/artigos/empreendedorismo/os-3-pilares-de-umnegocio-de-sucesso/97045/>. Acesso em: 26 nov. 2018.

SANTOS, S. A; PEREIRA, H. J. Criando seu próprio negócio: como desenvolver o potencial empreendedor. Brasília: Ed. SEBRAE, 1995. Disponível em https://bibliotecas.sebrae.com.br/chronus/ARQUIVOS_CHRONUS/bds/bds.nsf/76b24d971c 7df79dd7a904a397df305c/\$File/7600.pdf

SEBRAE. Beneficios de se tornar Empresario, 2017. Disponivel em https://bibliotecas.sebrae.com.br/chronus/ARQUIVOS_CHRONUS/bds/bds.nsf/76b24d971c 7df79dd7a904a397df305c/\$File/7600.pdf. Acesso em 25 ago 2018.

SEBRAE. Como o SEBRAE pode ajudar seu negócio, 2016. Disponivel em http://www.sebrae.com.br/sites/PortalSebrae/ufs/mt/noticias/como-o-sebrae-pode-ajudarseu-negocio,5438892adfd03510VgnVCM1000004c00210aRCRD. Acesso em 22 ago 2018.

SEBRAE. Entenda as diferenças entre microempresa, pequema empresa e MEI, 2018. Disponível em http://www.sebrae.com.br/sites/PortalSebrae/artigos/entenda-as-diferencasentre-microempresa-pequena-empresa-emei,03f5438af1c92410VgnVCM100000b272010aRCRD. Acesso em 22 ago 2018.

SEBRAE-SP. Estudo da mortalidade das empresas paulistas. Relatório final, São Paulo, dez. 1999.

SEBRAE. Participação da Micro e Pequenas Empresas na Economia Brasileira, 2014. Disponível em:

https://m.sebrae.com.br/Sebrae/Portal\%20Sebrae/Estudos\%20e\%20Pesquisas/Participacao\% 20das\%20micro\%20e\%20pequenas\%20empresas.pdf. Acesso em 22 ago 2018.

SEBRAE. Sobrevivência das empresas no Brasil, 2016. Disponível em https://m.sebrae.com.br/Sebrae/Portal\%20Sebrae/Anexos/sobrevivencia-das-empresas-nobrasil-102016.pdf. Acesso em 26 ago 2018.

SEBRAE. Taxa de Sobrevivência das empresas no Brasil, 2011. Disponível em http://www.sebrae.com.br/Sebrae/Portal\%20Sebrae/Anexos/Sobrevivencia_das_empresas_n o_Brasil_2011.pdf. Acesso em 23 ago 2018 
SILVA, João Braz. O Uso de Ferramentas de Gestão Empresarial como Fator de Sucesso dentro das Empresas - Um Estudo de Caso. Dissertação - Mestrado em Engenharia de Produção, UFSC, Florianópolis, 2004.

VELDEN, Marcelo Sabino de Oliveira Vander. CAUSAS DA MORTALIDADE DAS MICRO E PEQUENAS EMPRESAS NO BRASIL. 2004. 44 f. Monografia (Especialização) - Curso de Economia, Unicamp, Campinas, 2004. 